\title{
Method Development and Validation RP-HPLC Method for the Simultaneous Estimation of Levofloxacin Hemihydrate and Cefpodoxime Proxetil in Pharmaceutical Dosage Form
}

\author{
ANIL KUMAR VEERAGONI ${ }^{1 *}$, RANJEETH REDDY K ${ }^{2}$, \\ MALLADI SRINIVAS REDDY ${ }^{2}$, CHILAGANI ARUN KUMAR ${ }^{2}$, \\ VASUDEVA MURTHY SINDGI $^{3}$ and SHOBA RANI SATLA ${ }^{4}$ \\ ${ }^{1}$ Department of Pharmaceutical Analysis, \\ Pathfinder Institute of Pharmacy Education and Research, Warangal-Telangana, India \\ ${ }^{2}$ Department of Pharmaceutical Analysis and Quality Assurance, \\ Vaageswari College of Pharmacy, Karimnagar-505481, Telangana State, India \\ ${ }^{3}$ Jayamukhi College of Pharmacy, Narsampet Warangal, Telangana, India \\ ${ }^{4}$ Centre for Pharmaceutical Sciences, \\ Institute of Science and Technology, JNTUH, Hyderabad, Telangana, India \\ v_aneel@yahoo.co.in
}

Received 2 July 2016 / Accepted 3 September 2016

\begin{abstract}
A new simple, sensitive, accurate and precise method has been developed for the simultaneous estimation of Levofloxacin hemihydrate and Cefpodoxime proxetil in pharmaceutical dosage form by RP-HPLC. After optimization good chromatographic separation was achieved by isocratic mode with a mixture of $\mathrm{K}_{2} \mathrm{HPO}_{4}$ and methanol $\mathrm{pH} 8$ in the ratio of 40:60 v/v as the mobile phase with $\mathrm{YMC} \mathrm{C}_{18}(250 \mathrm{~mm} \times 4.6 \mathrm{~mm}$ i.d $\times 5 \mu \mathrm{m})$ column as stationary phase at flow rate of $1 \mathrm{~mL} / \mathrm{min}$ and detection wavelength of $275 \mathrm{~nm}$. The retention time of Levofloxacin hemihydrate and Cefpodoxime proxetil were found to be 2.8 and $3.9 \mathrm{~min}$ respectively. The linearity of this method was found in the concentration range of $250 \mu \mathrm{g} / \mathrm{mL}$ to $750 \mu \mathrm{g} / \mathrm{mL}$ for Levofloxacin hemihydrate and $200 \mu \mathrm{g} / \mathrm{mL}$ to $600 \mu \mathrm{g} / \mathrm{mL}$ for Cefpodoxime proxetil. The method was extensively validated according to ICH guidelines Q2B for Linearity, Range, Accuracy, Precision, Specificity and Robustness.
\end{abstract}

Keywords: High performance liquid chromatography, Levofloxacin hemihydrates, Cefpodoxime proxetil

\section{Introduction}

Chemically, Levofloxacin Hemihydrate is [(s)-9-fluro-2,3-dihydro-3-methyl-10-(4-methylpiperazin-1-yl)-7-oxo-7H-pyrido[1,2,3-de]-1,4-benzoxazine-6-carboxazine-6-carboxylic acid Hemihydrate $]^{1}$ as show in Figure 1. 
<smiles>C[C@@H]1COc2c(N3CCN(C)CC3)c(F)cc3c(=O)c(C(=O)O)cn1c23</smiles>

Figure 1. Structure of Levofloxacin Hemihydrate

Levofloxacin inhibits bacterial type II topoisomerases, topoisomerase IV and DNA gyrase. Levofloxacin, like other fluoroquinolones, inhibits the subunits of DNA gyrase, two subunits encoded by the gyrA gene. This results in strand breakage on a bacterial chromosome, supercoiling and resealing; DNA replication and transcription are inhibited ${ }^{2}$.

Chemically, Cefpodoxime Proxetilis [1(isopropoxycarbonyloxy) ethyl (6R, 7R)-7-[2-(2amino-4-thiazolyl)-(Z)-2(methoxyimino)acetamido]-3-methoxymethyl-3-cephem-4carboxylate $]^{3}$ as show in Figure 2.<smiles>COCC1=C(C(=O)OC(C)OC(=O)OC(C)C)N2C(=O)[C@@H](NC(=O)/C(=N\OC)c3csc(N)n3)[C@H]2SC1</smiles>

Figure 2.Structure of Cefpodoxime Proxetil

Cefpodoxime is active against a wide spectrum of Gram-positive and Gram-negative bacteria. Cefpodoxime is stable in the presence of beta-lactamase enzymes. As a result, many organisms resistant to penicillins and cephalosporins, due to their production of betalactamase, may be susceptible to Cefpodoxime. Cefpodoxime is inactivated by certain extended spectrum beta-lactamases. The bactericidal activity of Cefpodoxime results from its inhibition of cell wall synthesis. The active metabolite of cefpodoxime binds preferentially to penicillin binding protein 3 , which inhibits production of peptidoglycan, the primary constituent of bacterial cell walls ${ }^{4}$.

In the literature survey it was found that Levofloxacin and Cefpodoxime were estimated in combination drugs by Spectrophotometric ${ }^{5,6}$ and HPLC methods, ${ }^{7-9}$ Levofloxacin Hemihydrate and Cefpodoxime Proxetil alone in tablet dosage form ${ }^{10-13}$. The plan of work is to develop a simple, sensitive, accurate and precise method for its analysis in combination drug formulation. After a detailed study a novel RP-HPLC method was decided to be developed and validated.

\section{Experimental}

Pharmaceutical grade Levofloxacin Hemihydrate, Cefpodoxime Proxetil, methanol and water were supplied by Rainbow Parma training Lab., Hyderabad, India. Gudcef-L tablet was purchased from market for analysis. 
The analysis of the drug was carried out on a Waters HPLC system 2695 series consisting pump, auto sampler, photodiode array detector, thermostat column running on empower-2 software.Chromatographic separation was achieved on YMC C18 $(250 \mathrm{~mm} \times 4.6$ $\mathrm{mm}, 5 \mu$ ) column using mobile phase composition of $0.1 \mathrm{M}$ Dipotassium hydrogen ortho phosphate buffer: Methanol (40:60 v/v) $\mathrm{pH}$ 8. Flow rate was maintained at $1 \mathrm{~mL} / \mathrm{min}$ with detection $275 \mathrm{~nm}$. The retention time of Levofloxacin Hemihydrate and Cefpodoxime Proxetil were found to be 2.8 and 3.9 min respectively as show in Figure 3.

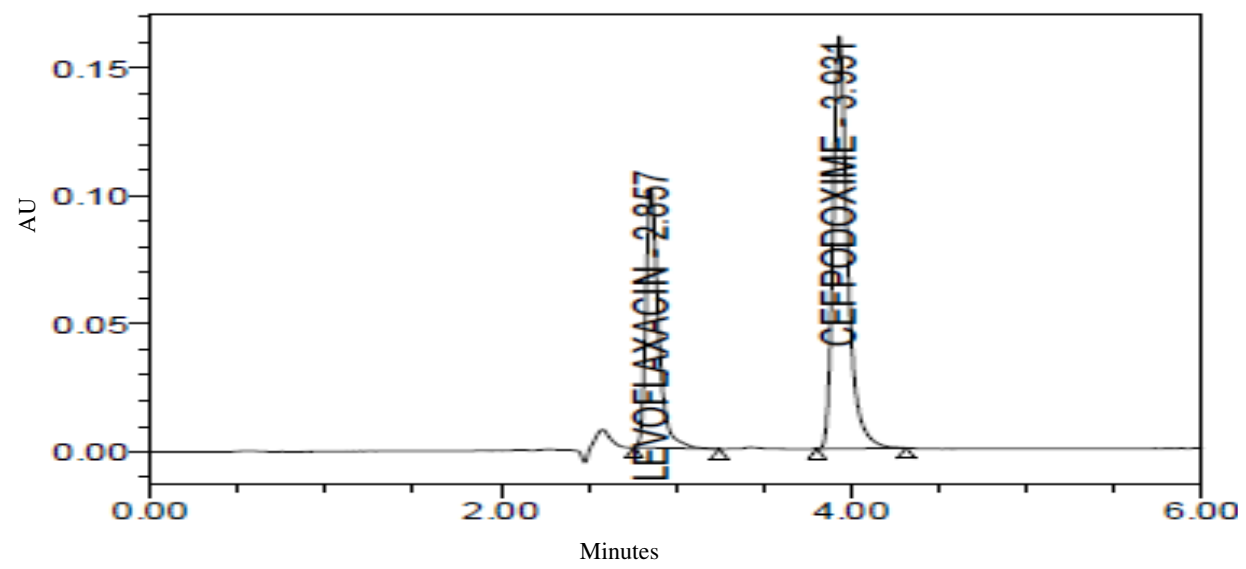

Figure 3. Chromatogram of Levofloxacin Hemihydrate and Cefpodoxime Proxetil

\section{Preparation of mobile phase}

The mobile phase was pumped by mixing $0.1 \mathrm{M}$ Dipotassium hydrogen orthophosphate: methanol in ratio of 40:60 v/v.

\section{Preparation of standard solution}

Standard combined solution was prepared by transferring accurately weighed $62.5 \mathrm{mg}$ of Levofloxacin Hemihydrate and $50 \mathrm{mg}$ Cefpodoxime Proxetil into a $25 \mathrm{~mL}$ of clean dry volumetric flask. Thereafter $10 \mathrm{~mL}$ of methanol was added. The result solution was sonicated to dissolve the drug and volume was made up to the mark with HPLC grade water. From the above standard solution, $5 \mathrm{mLwas}$ pipette into a $25 \mathrm{~mL}$ volumetric flask and diluted up to the mark with HPLC grade waterwhich is concentration $500 \mu \mathrm{g} / \mathrm{mL}$ and $400 \mu \mathrm{g} / \mathrm{mL}$ Levofloxacin Hemihydrate and CefpodoximeProxetilrespectively.

\section{Preparation of working standard solution}

Accurately weighed 20 tablets and transferred tablet powder equivalent to $250 \mathrm{mg}$ of Levofloxacin Hemihydrateand $200 \mathrm{mg}$ of Cefpodoxime Proxetil taken into a $100 \mathrm{~mL}$ clean dry volumetric flask and added about $20 \mathrm{~mL}$ of methanol. It was sonicated for $30 \mathrm{~min}$ to dissolve completely and volume up to the mark with the same HPLC grade water. This stock solution contains $2500 \mu \mathrm{g} / \mathrm{mL}$ of Levofloxacin and $2000 \mu \mathrm{g} / \mathrm{mL}$ of Cefpodoxime. From the above test stock solution, $5 \mathrm{~mL}$ of solution was pipette into a $25 \mathrm{~mL}$ volumetric flask and make up to the mark with HPLC grade waterwhich is of concentration $250 \mu \mathrm{g} / \mathrm{mL}$ and $200 \mu \mathrm{g} / \mathrm{mL}$ of Levofloxacin Hemihydrate and Cefpodoxime Proxetil respectively. 


\section{Optimization method}

To optimize the HPLC parameters, several mobile phase composition with different columns with different columns were tried. The optimized method had been concluded by theoretical plates, tailing and resolution achieved within limits. For the optimization condition in Figure 3 and Table 1.

Table 1.HPLC optimization condition

\begin{tabular}{cc}
\hline HPLC System & Water HPLC System 2695 Series \\
\hline Detector & PDA \\
Column & YMC Column $(250 \times 4.6 \mathrm{~mm}, 5 \mu \mathrm{m})$ \\
Mobile Phase & $0.1 \mathrm{M} \mathrm{K}_{2} \mathrm{HPO}_{4}$, Methanol $(40: 60)$ \\
Flow Rate & $1 \mathrm{~mL} / \mathrm{min}$ \\
Sample Volume & $10 \mu \mathrm{L}$ \\
Temperature & $30^{\circ} \mathrm{C}$ \\
Wavelength & $275 \mathrm{~nm}$ \\
Run time & $6 \mathrm{~min}$ \\
Retention time & LVF $-2.867 \mathrm{~min}$ and CEP-3.930 min \\
Theoretical plates & 8390 \\
Tailing & 1.41 \\
Resolution & 7.70 \\
\%RSD & $<1$ \\
\hline
\end{tabular}

\section{Results and Discussion}

\section{Method Validation: Linearity}

The calibration curves were obtained within the concentrations of the standard solutions of Levo $250-750 \mu \mathrm{g} / \mathrm{mL}$, Cefpo 200-600 $\mu \mathrm{g} / \mathrm{mL}$. From the linearity data in Table 2, the correlation coefficient for linear curve obtained between concentration vs. area for standard preparations of Levofloxacin Hemihydrate and Cefpodoxime Proxetil was 0.999, 0.999 respectively. The relationship between the concentration of Levofloxacin Hemihydrate and Cefpodoxime Proxetilarea of both drugs is linear in the range examined since all points lie in a straight line as shown in Figure 4 and 5 respectively and the correlation coefficient is well within limits.

Table 2. Linearity of Levofloxacin Hemihydrate and CefpodoximeProxetil

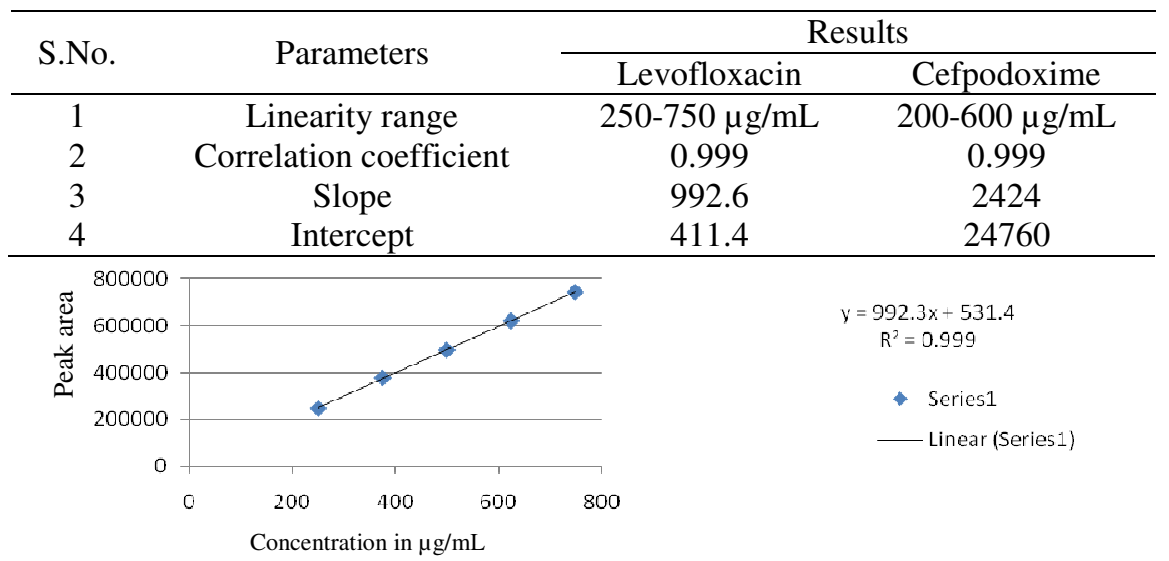

Figure 4. Linearity plot of Levofloxacin Hemihydrate 


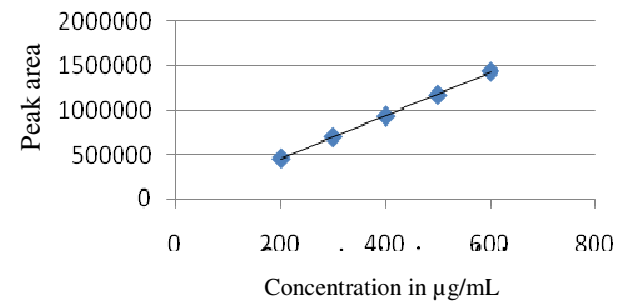

$$
\begin{gathered}
y=2424 \cdot x-24760 \\
R^{2}=0.999 \\
\quad \text { Series } 1
\end{gathered}
$$

Figure 5. Linearity plot of Cefpodoxime Proxetil

\section{System suitable parameters}

System suitability is the evaluation of the components of an analytical system to show that the performance of a system meets the standards required by a method. System suitability was evaluated by injecting the standard drugs of Levofloxacin Hemihydrate and Cefpodoxime Proxetil six times. The theoretical plates, tailing factor, resolution and \%RSD was found within limits (Table 1).

\section{Assay of tablet dosage form}

The sample peaks found to be without any interference. \% Assay was calculated and listed in Table 3 the values were found to be within limits (98-102\%).

Table 3. Assay results of Levofloxacin and Cefpodoxime in tablet dosage form

\begin{tabular}{cccc}
\hline Drug & Label claim & Amount found & \% Assay \\
\hline Levofloxacin & $250 \mathrm{mg}$ & 245.83 & $98 \%$ \\
Cefpodoxime & $200 \mathrm{mg}$ & 198.66 & $99 \%$ \\
\hline
\end{tabular}

\section{Accuracy}

The accuracy of the test method was demonstrated by preparing recovery samples of blend mixture at the level of 50\%, $100 \%$ and $150 \%$ of target concentration. The recovery samples were prepared triplicate at each level. The samples at different level were injected and the percentage recovery for the amount added was estimated. From the data of Tables 4 and 5 the $\%$ mean recovery for Levofloxacin Hemihydrate is 100 and for Cefpodoxime Proxetil is 100.

Table 4. Recovery studies of Levofloxacin Hemihydrate

\begin{tabular}{ccccc}
\hline S.No & Spiked Level, $\%$ & $\mu \mathrm{g} / \mathrm{mL}$ added & $\mu \mathrm{g} / \mathrm{mL}$ found & $\%$ Recovery \\
\hline 1 & 50 & 245 & 242.27 & 99 \\
2 & 100 & 490 & 490.97 & 100 \\
3 & 150 & 735 & 740.73 & 101 \\
\hline
\end{tabular}

Table 5. Recovery studies of Cefpodoxime Proxetil

\begin{tabular}{ccccc}
\hline S.No & Spiked Level, $\%$ & $\mu \mathrm{g} / \mathrm{mL}$ added & $\mu \mathrm{g} / \mathrm{mL}$ found & \% Recovery \\
\hline 1 & 50 & 198 & 198.08 & 100 \\
2 & 100 & 396 & 396.75 & 101 \\
3 & 150 & 594 & 594 & 100 \\
\hline
\end{tabular}

\section{Precision}

The precision of an analytical method is a measure of the random error and is defined as the agreement between replicate measurements of the same sample. It is expressed as the relative standard deviation (\%RSD) of the replicate measurements. The relative standard 
deviation (\%RSD) of 6 determinations of peak areas for Levofloxacin Hemihydrate and CefpodoximeProxetilfor precision was found to be within the acceptance criteria of less than $2.0 \%$ (Table 6).

Table 6. Precision studies for Levofloxacin and Cefpodoxime

\begin{tabular}{ccc}
\hline \multirow{2}{*}{ Average mean area } & Levofloxacin & Cefpodoxime \\
\cline { 2 - 3 } & 495467 & 935431 \\
\hline SD & 3716 & 3453 \\
\%RD & 0.7 & 0.3 \\
\hline
\end{tabular}

\section{$L O D$ and $L O Q$}

For this method, the LOD value was found to be $2.358 \mu \mathrm{g} / \mathrm{mL}$ for Levofloxacin Hemihydrate, $1.183 \mu \mathrm{g} / \mathrm{mL}$ for CefpodoximeProxetil. For this method, the LOQ value was found to be $7.862 \mu \mathrm{g} / \mathrm{mL}$ for Levofloxacin Hemihydrate, $3.944 \mu \mathrm{g} / \mathrm{mL}$ for CefpodoximeProxetil.

\section{Robustness}

As part of the Robustness, deliberate change in the temperature and flow rate composition was made to evaluate the impact on the method. From the results of robustness by variations in temperature and flow rate (Table 7), it was observed that not much variation in resolution, tailing factor and plate count was observed with deliberate changes in temperature and flow rate. The resolution, tailing factor and plate count was found to be within the limits for Levofloxacin Hemihydrate and Cefpodoxime Proxetil.

Table 7. Results of Robustness by variation in temperature and flow rate

\begin{tabular}{cccccc}
\hline \multirow{2}{*}{ Parameters } & \multirow{2}{*}{ Value } & \multicolumn{2}{c}{ Levofloxacin } & \multicolumn{2}{c}{ Cefpodoxime } \\
\cline { 3 - 6 } & & RT & Area & RT & Area \\
\hline \multirow{3}{*}{ Temperature } & $25^{\circ} \mathrm{C}$ & 3.1 & 544072 & 4.2 & 1032295 \\
& $30{ }^{0} \mathrm{C}$ & 2.8 & 503783 & 3.9 & 943568 \\
& $35{ }^{\circ} \mathrm{C}$ & 2.6 & 455398 & 3.6 & 872582 \\
Flow rate & $0.8 \mathrm{~mL} / \mathrm{min}$ & 3.1 & 542209 & 4.2 & 1030353 \\
& $1 \mathrm{~mL} / \mathrm{min}$ & 2.9 & 513783 & 3.9 & 94356 \\
& $1.2 \mathrm{~mL} / \mathrm{min}$ & 2.6 & 455596 & 3.6 & 865303 \\
\hline
\end{tabular}

\section{Conclusion}

A new simple, sensitive, accurate and precise method was developed by RP-HPLC for the simultaneous estimation of Levofloxacin Hemihydrate and Cefpodoxime Proxetilin combined tablet dosage form. After observing all the satisfactory results in optimized chromatographic conditions and validation parameters, the $\%$ recovery was found $100 \%$. It indicates the accuracy of the method. The \%RSD was found less than $1 \%$ it indicates the method is precise. It was concluded that this method is specific and selective for Levofloxacin Hemihydrate and Cefpodoxime Proxetil as there were no excipient peaks in Chromatogram. From the results of robustness it was found that a little variation in methods does not affect the intended use.

\section{References}

1. Indian Pharmacopoeia. The India Pharmacopoeia commission. Vol 2 Ghaziabad, 2007, 678.

2. Rang \& Dale's, Pharmacology, $6^{\text {th }}$ Edn., 2007, 672.

3. Harkishan Singh, Medicinal and Pharmaceutical Chemistry, $3^{\text {rd }}$ Edn., 2012, 572.

4. Satoskar, Pharmacology. $20^{\text {th }}$ Edn., 2012, 677. 
5. Tamilarasi G, Vetrichelvan T, Venakappayya D, Tharabai R and Yuvarajan K, Int $J$ Pharm Sci., 2014, 6, 646-648.

6. Rajeshree C K, Savaliya B M, Lakkad A J, Soriya S V, Kapuriya K G and Faldu S D, Int Bulletin Drug Res., 2012, 2(3), 22-30.

7. Shivangi D P and Farhatjahan Shaikh, World J Pharm \& Pharmaceutical Sci., 2014, 6, 921-940.

8. Spandana K, Rathnakar Ch and Kole Bhavana, Material Science Research India, 2014, 11, 67-73; DOI:10.13005/msri/110109

9. Rajeshree K, Birju Savalaia, Arvind Lakkad, Kaushik Kapuria and Shital Faldu, Inventi Rapid - Pharm Analysis \& Quality Assurance, 2013, 2,150-159.

10. Manasa P, Vasanth P M, Ramesh T and Ramesh Molathu, Int J Bio Phrma Res., 2012, 7, 918-928.

11. Narasimha S and Nishant G, Int J Res Pharm Sci., 2011, 2(1), 45-51.

12. Patel G and Rajput S, Acta Chromatographica., 2011, 23(2), 215-234; DOI:10.1556/AChrom.23.2011.2.3

13. Gopi N and Narasimha Rao D, World J Pharm Pharmaceutical Sci., 2013, 2(5), 3596-3603. 